\title{
The Formation Mechanism of Surface Landslide Disasters in the Mining Area under Different Slope Angles
}

\author{
Chi Mu (i), ${ }^{1,2}$ Xueyi Yu, ${ }^{2}$ Bingchao Zhao, ${ }^{2}$ Dongdong Zhang, ${ }^{2}$ Xuwei Mao, ${ }^{2}$ and Jun $\mathrm{Zhu}^{3}$ \\ ${ }^{1}$ Shaanxi Provincial Land Engineering Construction Group, Xi'an 710075, China \\ ${ }^{2}$ School of Energy Enginesering, Xi'an University of Science and Technology, Xi'an 710054, China \\ ${ }^{3}$ School of Marine Science and Technology, Northwestern Polytechnical University, Xi'an 710072, China \\ Correspondence should be addressed to Chi Mu; muc@stu.xust.edu.cn
}

Received 15 October 2020; Revised 14 January 2021; Accepted 28 January 2021; Published 18 February 2021

Academic Editor: Timothy O. Olawumi

Copyright (c) $2021 \mathrm{Chi} \mathrm{Mu}$ et al. This is an open access article distributed under the Creative Commons Attribution License, which permits unrestricted use, distribution, and reproduction in any medium, provided the original work is properly cited.

\begin{abstract}
Slope stability analysis is important for the safe mining of mineral resources. The collapse of goafs in loess gullies can lead to natural disasters such as surface landslides. In this context, this study analyzes monitoring data obtained from surface observation in the Shendong mining area of the Hanjiawan coal mine based on the geological conditions therein. The monitoring results show that the working face experiences a starting period, an active period, and a declining period, from the start of mining to the end of the working face. At the initial mining stage, there is no evident surface movement or deformation in the mining area. When the advance distance of the 12106 working face is between $13 \mathrm{~m}$ and $109 \mathrm{~m}$, the surface movement and deformation vary significantly, and the maximum subsidence reaches $1963 \mathrm{~mm}$, which is enough to cause landslides. We select the physical and mechanical parameters of the rock and soil in the mine and then simulate the formation mechanism of surface landslides under different slope angles of the mining area using FLAC3D software. Because of the collapse of the mined-out area, the overlying strata structure is destroyed, the subsidence basin is shifted to the center as a whole, and the slope mass is subjected to tensile and compression deformation, resulting in plastic damage, which develops downward along the crack and leads to a collapse because of the discontinuous movement and deformation of the surface; moreover, step-type ground fissures are produced. The results also show that when the slope angle is greater than $60^{\circ}$, the displacement of the slope mass is not uniform, and the rock stratum in a position with large displacement loses its support, leading to landslides; when the slope angle is less than $30^{\circ}$, the bedrock surface forms a sliding surface and develops to the surface, thus decreasing the possibility of landslides. Based on the stability analysis of the collapsed slope in the goaf of the loess gully, a scientific basis is provided for the effective prevention and control of geological disasters in the Shendong mining area.
\end{abstract}

\section{Introduction}

Loess gullies in China are mainly distributed in the northwest region. A loess gully is a special geological structure located in the transition zone between the plain and plateau regions. The erosion of the cover layer of loess gullies can lead to steep trenches due to rain erosion, making the geological conditions in such areas quite complex $[1,2]$. Due to the significant surface water and soil loss in loess gullies, the ravines are crisscrossed. Conducting coal seam mining under such geological conditions can lead to surface subsidence or even geological disasters such as landslides, collapses, and debris flows [3]. A loess gully area mainly includes three types of landforms: a loess hilly gully area, loess remnant gully area, and loess plateau gully area. The frequency of geological disasters in loess gullies is higher than that in plains. The more serious types of hazards are landslides, ground fissures, surface subsidence, debris flow, and cavern collapses [4]. The loess gully in Shendong mining area occupies a significant portion of the entire mining area, and the surface is covered by loess, with a thickness in the range of approximately $70-80 \mathrm{~m}[5,6]$. Under natural conditions, due to external forces, such as geological movement and rain erosion, the loess exhibits some special 
characteristics as undulating terrain, damaged surfaces, thick loess-layer covering, and high gully density.

Recent years have witnessed an increase in comprehensive research on mining disaster management by the Chinese mining industry and research groups, making it one of the latest hot topics of research. Chen et al. $[7,8]$ considered twelve landslide-related parameters for landslide susceptibility mapping, including slope angle, slope aspect, plan curvature, profile curvature, altitude, land use, distance to faults, distance to roads, distance to rivers, lithology, and rainfall. Liu et al. [9, 10] obtained the distribution of the geological strength index (GSI) using geostatistics-based methods to determine the spatial variability of the mechanical parameters. The mechanical parameters of a rock mass in mining engineering can be characterized by spatial variability and time decay, and these play an important role in slope stability analyses. Li et al. [11-14] explored the evolution of landslides in different stages and divided the landslide deformation process into four stages: initial deformation, uniform deformation, accelerated deformation, and abrupt deformation. The correlation analysis method was used to determine the characteristics of landslides in the study area. Zhang [15] selected mountain coal mines as the research object and, based on field measurement data, used the Moore-Coulomb criteria to calculate the distribution of the surface stress mining landslide cracks and potential landslide areas. Huang [16] established a surface movement and deformation observation station in the first mining face of the Zhaojiazhai coal mine, summarized the characteristics of surface cracks, and calculated the boundary angle, movement angle, and maximum subsidence value and maximum subsidence velocity of the mining face. Liu [17] analyzed the movement and deformation laws of the surface, combined with surface monitoring data of the mining face of the Ningtiaota coal mine, and carried out a numerical simulation of the mining of the working face.

Hungr et al. [18-20] recommended to modify the definition of landslide-forming materials to be compatible with the accepted geotechnical and geological terminologies of rocks and soils. Bui et al. [21, 22] explored some new state-of-the-art sophisticated machine learning techniques and introduced a framework for training and validating of shallow landslide susceptibility models using the latest statistical methods. Corominas et al. [23-25] recommended methodologies for the quantitative analysis of landslide hazard, vulnerability, and risk at different spatial scales (site-specific, local, regional, and national), as well as for the verification and validation of the results. Lucieer et al. [26-28] presented a flexible, cost-effective, and accurate method to monitor landslides using a small unmanned aerial vehicle (UAV) for aerial imaging. Tehrany et al. [29] provided an overview of recent literature on high-resolution topographic analyses and introduced airborne and terrestrial technologies for high-resolution topography, opening avenues for the analysis of landslides, hillslopes, and channelization processes. Trigila et al. $[30,31]$ defined reliable susceptibility models for shallow landslides using logistic regression and random forest-based multivariate statistical techniques.

Although previous studies have provided valuable insights into the characteristics of loess gullies, they have not considered the mining of mineral resources under special engineering geological conditions with loess gullies as the engineering background. In this context, because the mining of mineral resources can influence the stress state of the overlying rock layer, we consider the engineering geology of the loess gully area as the background and classify the soil slopes into different types. Moreover, we calculate the subsidence amount and subsidence speed of the ground movement deformation during the start-up, active, and recession periods, combined with the mining conditions of the Hanjiawan coal mine working face, the profile layout obtained from surface movement observation, and based on monitoring data, and analyze the rock and soil mechanical parameters of the slope mass, using FLAC3D software. The displacement vectors of the 12106 working face of the Hanjiawan coal mine under different slope conditions are analyzed in the horizontal and vertical directions, and the destruction rules of the plastic zone are determined.

\section{Slope of Loess Gullies}

2.1. Slope Failure Types. In China, the loess gully area is a special terrain structure, widely distributed in the northern Shaanxi area, and its slope mass deformation is complex. The mining of coal resources causes surface movement and deformation, which increases the risk of geological disasters. The loess gullies have unique mechanical characteristics and special geological structures. In the dry season and alternating rainy season, the deformation characteristics of the area are quite complex. Based on a field survey of the loess gullies, geological experts have categorized the damage of loess gullies into four types: collapse, spalling, landslide, and ground fissure.

2.1.1. Collapse. If the joint surface of the soil slope tends to slip and dislocate, it is affected by its own weight, and the phenomenon of overall collapse of the slope mass is called collapse [32]. The large slope angle of the loess layer and the height of the accumulation layer are the main reasons for the collapse. Given the large thickness of the topsoil layer and the high degree of vertical crack development in the loess gully area, the slope mass may collapse due to rain erosion, strong winds, and/or sand corrosion in a short period of time, and the collapsed soil will generally accumulate in blocks at the foot of the slope. Because the loess layer contains coarse gravels and is eroded by rain and wind for long durations, the massive amount of soil accumulated at the foot of the slope will form a second collapse. Serious surface deformation has been caused by mining, resulting in surface cracks as wide as $2 \mathrm{~m}$ and as deep as $15-20 \mathrm{~m}$, as shown in Figure 1. 


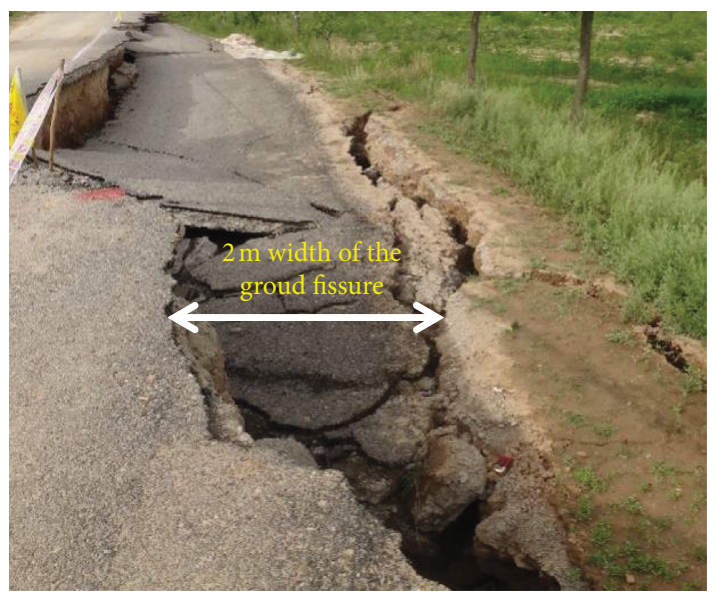

FIGURE 1: Coal mining caused ground subsidence and formed a $2 \mathrm{~m}$ width of ground fissure.

2.1.2. Spalling. Slope soil layer spalling is a common movement and deformation mechanism in loess gullies. This phenomenon is likely to occur in every loose soil layer; however, the soil layer structures and regions have different characteristics [33]. Because the movement and deformation are scattered widely in this type of stratum structure, they have no integrity or continuity, so there is no specific remediation plan. Affected by precipitation and natural weathering, the stratum structure of the loess gully region changes, soil nutrients are lost, and plant roots are destroyed. Many types of soil spalling occur on slopes, mainly including layered spalling, massive spalling, and flaking. Moreover, the scales flake off, as shown in Figure 2.

2.1.3. Landslide. In the topographical conditions of the loess gully, the site where significant slippage occurs along the slope of the soil is called a landslide. The top of the slope is relatively steep, and the toe of the slope is generally gentle [34]. Loess slopes have been eroded in the natural environment for a long time, causing damage to the structure of the slope, reducing the pressure strength of the soil in the loess gully area, leading to the destruction of the stability of the loess slope, and causing landslide disasters. At the same time, the influence of underground coal seam mining in loess gully areas on surface movement and deformation is extremely complicated. Due to the discontinuity of its change process and the looseness of soil, the weight of loess slopes will also cause surface movement and deformation and landslides.

2.1.4. Ground Fissure. Ground fissures are the main type of surface mining damage in loess gully areas. Surface cracks in the loess overburden can be divided into closed cracks and permanent cracks. Closed cracks follow the advancement of the working face, and pull cracks appear in front of the working face [35]. After pushing through the cracks for a certain distance, the cracks are closed and appear along the mining face at a certain step. Permanent cracks are mainly concentrated near the boundary of the goaf, and large cracks

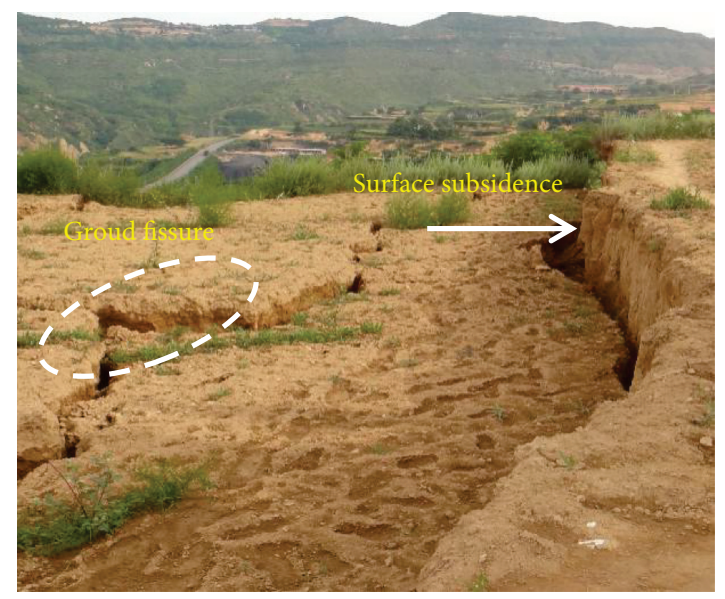

Figure 2: Soil nutrient loss caused surface desertification.

in groups of three to five are accompanied by the generation of secondary cracks. This type of crack damage is detrimental to surface construction facilities, arable land, surface vegetation, and groundwater.

2.2. Effect of Precipitation on Slope. The loess gully area is a unique landform type in the west of China, and its composition structure is relatively single. The loess is typically in the form of blocks and powder. Due to the influence of the large pore structure of the soil body, the loess gully area has a high degree of fissure development in the vertical direction and can have a higher stability in a dry environment, but in a precipitation environment, the soil layer will absorb water and soften, and its strength will decrease. Moreover, the loess layer exhibits different characteristics when it encounters water. Scanning electron microscopy (SEM) has been applied to scan the loess in the precipitation and arid areas to observe the structural changes in different regional environments [36, 37]. Due to the high degree of porosity development in the loess gullies under precipitation conditions, rainwater can penetrate the slope mass up to the bottom, which affects its stability.

Precipitation is the main factor causing landslides in the gully regions of loess plateaus. Rain can lead to landslides via four main mechanisms: loosening of the soil due to heavy rainfall, rise in the river bed, flooding of reservoirs, and destruction of intercepting dams [38]. Affected by rainwater environment, the main soil layer structure in the loess gully area is loose, mainly manifesting in the displacement of the slope from high to low; the cohesion and internal friction angle are reduced; the stability of the slope mass deteriorates, and the slope surface is gradually affected by the bedrock sliding surface. This, coupled with factors such as mining, can easily cause landslides.

To study the impact of rain on the loess layer, the soil samples in the precipitation and arid areas were scanned using an electron microscope and magnified 300 times for a comparative analysis. Figure 3 shows the SEM results. The SEM images of the loess show that the water environment has a significant effect on the soil structure. Before 


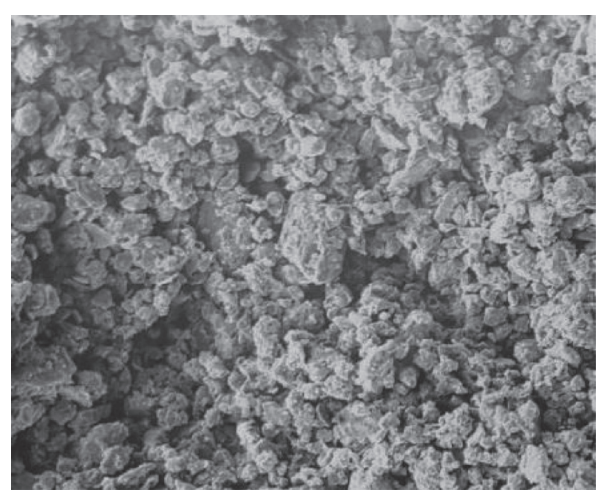

(a)

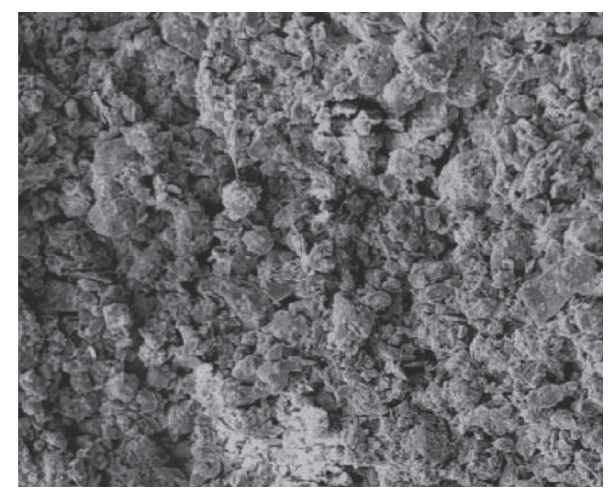

(b)

Figure 3: Scanning electron micrographs of loess: (a) 300 times magnification without water; (b) 300 times magnification in the case of water.

encountering the water, the loess particles are evenly distributed in space and have a high strength; after the encounter, the loess particles are cemented, and the pore structure is closely arranged, with evident collapsibility.

\section{Analysis of Landslide Characteristics and Slope Stability}

3.1. Engineering Geological Conditions. The Hanjiawan coal mine is sandwiched between the Qingshuichuan graben, the regional tortuous belt, and the Yellow River. The geological conditions around the mining area are complex, and the mineral resource occurrence structure is single. The overall stratum exhibits a monoclinic structure in the northwest direction. The regional stratum structure is relatively gentle, with a dip angle in the range of $2-9^{\circ}$; however, in the fold zone and westward, the stratum occurrence quickly steepens, and the slope angle is up to $30^{\circ}$. This section provides an overview of the study area. The Hanjiawan coal mine is located at the northern end of the Shendong mining area. The north-south exploration area is $6.5-10.8 \mathrm{~km}$ long, and the exploration area is $46.52 \mathrm{~km}^{2}$; it is located in Yulin City, Shaanxi Province. The area is characterized by low hills of the loess plateau in northern Shaanxi (Figure 4). It is a typical loess plateau landform. The surface is mostly covered by loose layers and thick collapsible loess. The rock outcrop is only located in the valley and slope transition zone. The ravines are vertical and horizontal, and the terrain is steep. Affected by natural factors, the terrain is seriously damaged, the valley is cut deep, the slope is steep, and the shape is " $V$." There are many dangerous rocks in the valley, with steep ridges all over; the gully bed is mostly covered by alluvial deposits with small thickness; the bedrock is exposed locally; the bedrock on the valley slope is exposed on a large area and partly covered by residual slope deposits, and the thickness is not large.

3.2. Mining Landslide Characteristics. The western loess gully area is located in the transition zone of the crustal ascent and descent. If the slope mass has sufficient stability, it will not form a landslide. The edge of the valley bottom in the loess gully is steep, and the angle of the slope mass is greater than $30^{\circ}$ on average, i.e., the slope below the valley edge is close to or greater than the friction angle $\left(21-32^{\circ}\right)$, indicating that the structural stability of the slope mass is poor. The valleys in the loess gullies are cut in a crisscross pattern, and the relative height typically ranges from tens of meters to hundreds of meters. The loess layer has been cut below the loess layer. This unique erosion of the loess provides a platform for landslides. In addition, the loess layer structure in the groundwater seepage layer is below the water-proof layer, and its stratum structure is unstable [39-41]. Due to the influence of lithology, structure, and gully topography, the stability of the bottom of the slope mass is poor.

In the mining area of the mine valley, due to the large slope of the valley and the poor stability of the slope mass, this area is the most active area of mountain landslides. At the same time, the river has an erosive effect on the slope mass. The occurrence of landslides has a direct impact. As the weak parts of the loess gully area were eroded, the valleys were cut to a greater extent, causing significant damage to the surface and creating favorable conditions for the occurrence of landslides. The common features of surface subsidence and mining landslides caused by mining are that the high-displacement parts of the slope move along the landslides and the low-displacement parts, and the landslides have a direct effect on the surface deformation [42-44]. The surface soil layer in the slope mass is generally affected by nonuniform stress. The depth of surface crack development and the height of step subsidence determine the slope range of the slope mass. The landslide is a part of the rock slope along the free surface and slides to a low displacement in the form of relative sliding. The scope of the landslide is closely related to the mining area but mainly depends on the mining geological conditions.

3.3. Evaluation of Land Destruction in the Mining Area. Affected by the natural environment, the slopes in the study area are deeply cut in the longitudinal direction and are prone to surface movement and deformation. For the special 


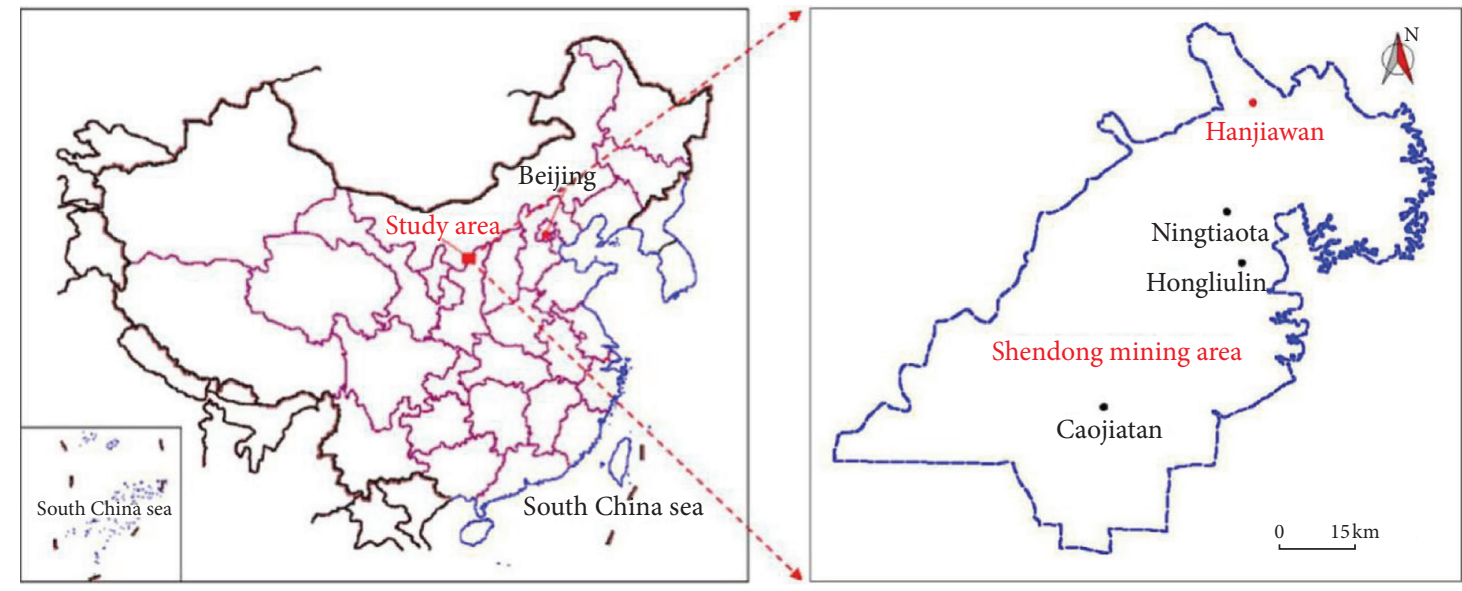

Figure 4: Location of the study area.

geological structure in the loess gullies, the slope stability $G$ serves as an index of the terrain mining conditions [45-48]. The slope stability can be expressed in terms of the main influencing factors as follows:

$$
G=\frac{h \gamma \sin (2 \delta)}{2 c+h \gamma(\sin \delta \cos \delta)^{2}},
$$

where $\delta$ is the slope angle $\left({ }^{\circ}\right) ; h$ is the slope height $(\mathrm{m}) ; \gamma$ is the soil density $\left(\mathrm{kg} / \mathrm{m}^{3}\right) ; c$ is the slope cohesion $(\mathrm{kPa})$; and $\varphi$ is the internal friction angle $\left({ }^{\circ}\right)$. In order to analyze the influence of the five factors on the slope stability, the orthogonal experiment method is used to calculate the slope stability under different factors. For the convenience of research, the basic slope model in this experiment is a homogeneous soil slope. The slope angle is $25^{\circ}$, the slope height is $30 \mathrm{~m}$, the soil density is $1700 \mathrm{~kg} / \mathrm{m}^{3}$, the slope cohesion is $10 \mathrm{kPa}$, and the internal friction angle is $16^{\circ}$. In order to fully analyze the effects of different influencing factors, five factors and three levels are selected for calculation [45-48]. The value range of each factor is divided into three levels (see Table 1). Assume that each factor has no interaction, that is, the number of calculations is 9 times, and the calculation results are shown in Table 2.

The calculation results show that there is a difference in the stabilities of each level of the slope mass. The difference method is used to calculate the difference between the maximum and minimum values of each level of stability; $R$ (= $\left.R_{\max }-R_{\min }\right)$ indicates the slope mass. The greater the degree of discreteness of the structure, the greater the $R$ value, indicating that the factor at this level has a greater impact on the slope stability, and it also reveals that the amount of change in this factor will significantly influence the calculation results [49-51]. Table 3 lists the range analysis results.

The range calculation results show that the range $R_{\delta}$ of the slope angle is greater than the range $R$ of the other influencing factors, and the magnitude of the range of each factor is ranked as follows: $R_{\delta}>R_{h}>R_{\gamma}>R_{\varphi}>R_{c}$, the slope angle changes relative to other factors. It has a significant influence on the stability of the slope mass, and the range $R_{c}$ of the cohesion within the slope is the lowest among the
TABLE 1: Various factors and values of slope stability.

\begin{tabular}{lccccc}
\hline Level & $\delta\left(^{\circ}\right)$ & $h(\mathrm{~m})$ & $\gamma\left(\mathrm{kg} / \mathrm{m}^{3}\right)$ & $c(\mathrm{kPa})$ & $\varphi\left(^{\circ}\right)$ \\
\hline 1 & 20 & 20 & 1600 & 5 & 12 \\
2 & 25 & 30 & 1700 & 10 & 16 \\
3 & 30 & 40 & 1800 & 15 & 20 \\
\hline
\end{tabular}

TABLe 2: Calculation results of slope stability.

\begin{tabular}{lcccccc}
\hline Number & $\delta\left(^{\circ}\right)$ & $h(\mathrm{~m})$ & $\gamma\left(\mathrm{kg} / \mathrm{m}^{3}\right)$ & $c(\mathrm{kPa})$ & $\varphi\left(^{\circ}\right)$ & $G$ \\
\hline 1 & 3 & 3 & 2 & 1 & 3 & 0.285 \\
2 & 3 & 1 & 3 & 2 & 2 & 0.477 \\
3 & 3 & 2 & 1 & 3 & 1 & 0.348 \\
4 & 2 & 3 & 2 & 1 & 2 & 1.251 \\
5 & 2 & 2 & 1 & 2 & 3 & 0.532 \\
6 & 2 & 1 & 3 & 3 & 1 & 0.357 \\
7 & 1 & 3 & 1 & 2 & 1 & 0.916 \\
8 & 1 & 2 & 2 & 3 & 3 & 1.051 \\
9 & 1 & 1 & 3 & 1 & 2 & 0.673 \\
\hline
\end{tabular}

TABle 3: Range analysis results.

\begin{tabular}{lccccc}
\hline Number & $\delta\left(^{\circ}\right)$ & $h(\mathrm{~m})$ & $\gamma\left(\mathrm{kg} / \mathrm{m}^{3}\right)$ & $c(\mathrm{kPa})$ & $\varphi\left(^{\circ}\right)$ \\
\hline$R_{1}$ & 2.640 & 1.507 & 1.796 & 2.209 & 1.621 \\
$R_{2}$ & 2.140 & 1.931 & 2.587 & 1.925 & 2.401 \\
$R_{3}$ & 1.110 & 2.497 & 1.707 & 1.756 & 1.868 \\
$R$ & 1.530 & 0.990 & 0.880 & 0.453 & 0.780 \\
\hline
\end{tabular}

factors. This indicates that the change in the cohesion within the slope has the lowest impact on the stability of the slope, the height of the slope, the bulk density of the slope, and the friction within the slope. The degree of influence of the angle on the slope stability is between those of the slope angle and height.

\section{Law of Surface Movement and Deformation}

The mining of mineral resources can lead to dynamic changes in the surface movement and deformation. The change in this process parameter is extremely complicated, and each surface monitoring point undergoes sinking, bending, tilting, and 
other phenomena. Therefore, it is necessary to study the law of surface movement and deformation during mining.

4.1. Establishment of Surface Observation Station. The layout of the surface mobile observation stations is divided into mesh and profile types. Table 4 gives an overview of the mobile observation stations on the working face. Combined with the actual situation of the 12106 working face of the Hanjiawan coal mine, the observation station is selected to be profiled. The inclined observation line B is parallel to the working face, $227 \mathrm{~m}$ away from the 12106 working face, and the horizontal observation line $\mathrm{A}$ is closer to the mountain boundary on the 12106 working face and perpendicular to the inclined vertical observation line B. It is laid out $116 \mathrm{~m}$ away from the transportation lane, and three control points are arranged in the southern section of the strike observation line, with the point numbers denoted by KA1-KA3; and 35 observation points are arranged along the strike observation line, with the point numbers denoted by ZA1-ZA35. A trend observation line is marked perpendicular to the trend observation line. The trend observation line $B$ has a total length of $1120 \mathrm{~m}$ and is $215 \mathrm{~m}$ away from the stop line. A total of five control points are arranged on both sides of the trend observation line. The point numbers are denoted by KB1-KB5. There are 55 observation points on the line, and the point numbers are denoted by ZB1-ZB55. The spacing between the measuring points is $5 \mathrm{~m}$.

4.2. Surface Subsidence Rate and Height. From the start of mining to the end of the working face, the surface movement and deformation undergoes three periods: start-up period, active period, and recession period. The surface subsidence velocity $v \leq 1.67 \mathrm{~mm} / \mathrm{d}$ during the start-up period and active period, and the surface subsidence velocity $v>1.67 \mathrm{~mm} / \mathrm{d}$ during the recession period. As the mining area of the working face continues to expand, the collapsed area of the mined-out area expands, and the subsidence speed and surface subsidence range of the monitoring point also increase dramatically. When the subsidence speed of the surface remains unchanged, the mining of the working face reaches the full mining state. As the mining surface continues to expand, the surface subsidence speed decreases, and as mining on the mining face is stopped for some period, the subsidence speed of each monitoring surface gradually returns to zero.

Based on the monitoring data of the measuring point $Z 3$, Figures 5 and 6 show that the advancing distance of the working face is related to the sinking amount and sinking speed of the surface monitoring point. When the advancing distance of the working face is less than $13 \mathrm{~m}$, the surface sinks. The amount is small, and the sinking speed of the corresponding monitoring point is also very low. At this time, the surface movement and deformation are in the starting period; as the working face continues to advance and when the advancing distance is between $13 \mathrm{~m}$ and $109 \mathrm{~m}$, the surface movement and deformation are in the active period. The amount of surface subsidence and the rate of subsidence increase significantly. When the subsidence rate reaches the maximum value, the increase in the amount of surface subsidence decreases, and this slow growth state lasts for a long time. This is due to the length of the roof hanging after the mining face is mined. A sinking speed is generated when the working face pushes a certain distance across the monitoring point, and the amount of ground subsidence will also increase significantly. When the working surface roof pressure step reaches the suspending distance, the basic roof collapses and fills the mined-out area below the surface. Accordingly, the sinking amount and sinking speed are reduced. When the advancing distance is greater than $109 \mathrm{~m}$, the surface movement and deformation enter the recession period, and the rate of change in the subsidence amount and subsidence speed no longer increases. As the working surface continues to advance, the surface parameter tends to be stable and close to zero.

\subsection{Model for Ground Movement and Deformation.} According to the surface monitoring data, the 12106 working face of the Hanjiawan coal mine is inadequately mined, the direction perpendicular to the mining face is fully mined, and the direction parallel to the mining face is inadequately mined; the surface sinks in inflection point. The offset is $d$, and the width of the main section of the mobile subsidence basin is $l$ [52-55]. Combined with the superposition law of the surface subsidence, the calculation formula for the surface subsidence under the mining geological conditions can be expressed as follows:

$$
w^{0}(y)=\frac{w_{\max }}{r} \int_{0}^{l} e^{\left(\pi / r^{2}\right)(y-s)^{2}} \mathrm{~d} s .
$$

Let $(\sqrt{\pi} / r)(y-m)=\phi, \quad$ then $\quad d m=-(r / \sqrt{\pi}) \mathrm{d} \phi$. Substituting these relationships into equations (2) yields

$$
\begin{aligned}
w^{0}(y) & =\frac{w_{\max }}{\sqrt{\pi}} \int_{(\sqrt{\pi} / r)(y-l)}^{(\sqrt{\pi} / r) y} e^{-\phi^{2}} \mathrm{~d} m \\
& =\frac{w_{\max }}{2}\left[\frac{2}{\sqrt{\pi}} \int_{0}^{(\sqrt{\pi} / r) y} e^{-\phi^{2}} \mathrm{~d} \phi-\frac{2}{\sqrt{\pi}} \int_{0}^{(\sqrt{\pi} / r)(y-l)} e^{-\phi^{2}} \mathrm{~d} \phi\right] \\
& =\frac{w_{\max }}{2}\left\{\left[1+\operatorname{erf}\left(\sqrt{\pi} \frac{y}{r}\right)\right]-\left[1+\operatorname{erf}\left(\sqrt{\pi} \frac{y-l}{r}\right)\right]\right\} \\
& =w(y)-w(y-l),
\end{aligned}
$$

where $w_{\max }$ is the maximum surface subsidence, $(\mathrm{m}) ; w^{0}(y)$ is the surface subsidence under insufficient mining conditions, $(\mathrm{m}) ; w_{\max }$ is the distance from any point on the sinking basin to the center of the goaf, $(\mathrm{m}) ; l+2 d$ is the mining width of the working face, $(\mathrm{m})$; $r$ is the main influence radius, (m).

From equation (3), we can conclude that a semiinfinite mining is formed by superimposing two semiinfinite mining trends at arbitrary positions $y$ and $y-l$, parallel to the working face [56]. According to the law of semi-infinite mining by finite element, $w(y)$ represents the partial coal seam mining at the mining face when the 
TABLE 4: Overview of surface mobile observation stations.

\begin{tabular}{|c|c|c|c|c|}
\hline \multirow{2}{*}{ Name of observation line } & \multirow{2}{*}{ Length of observation line (m) } & \multicolumn{2}{|c|}{ Observation points } & \multirow{2}{*}{ Monitoring point spacing $(\mathrm{m})$} \\
\hline & & Control point & Monitoring point & \\
\hline Horizontal observation line A & 760 & 3 & 35 & 15 \\
\hline Vertical observation line B & 1120 & 5 & 55 & 8 \\
\hline Total & 1880 & 8 & 90 & 23 \\
\hline
\end{tabular}

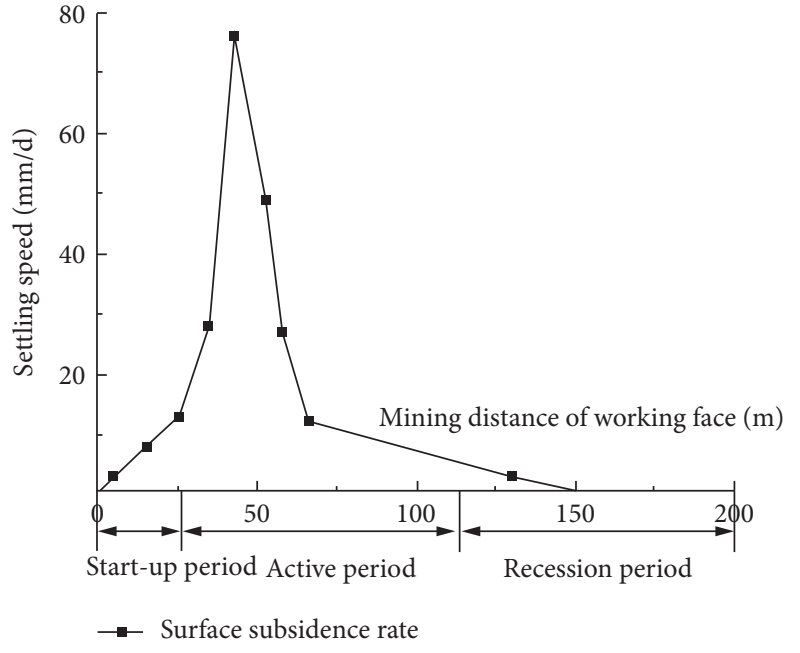

Figure 5: Surface subsidence rate.

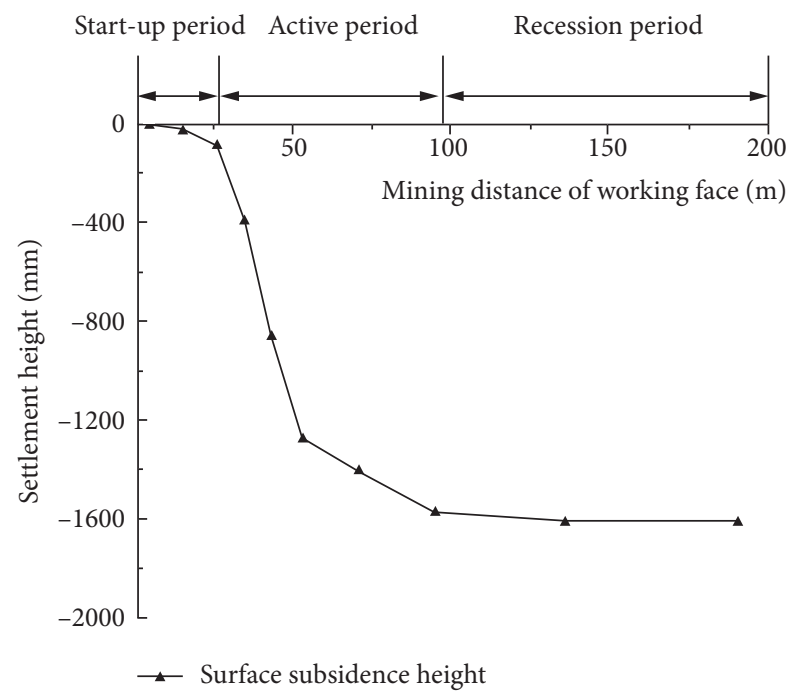

FIgURE 6: Surface subsidence height.

mining position $m=0 ; w(y-l)$ represents the semiinfinite mining condition at the mining face when the mining position $m=l$. Figure 7 shows the semi-infinite stacking algorithm.

4.4. Surface Movement and Deformation Parameters. The surface movement and deformation are affected by many factors. The physical properties of the overlying strata, the mining width, and the mining speed of the working face

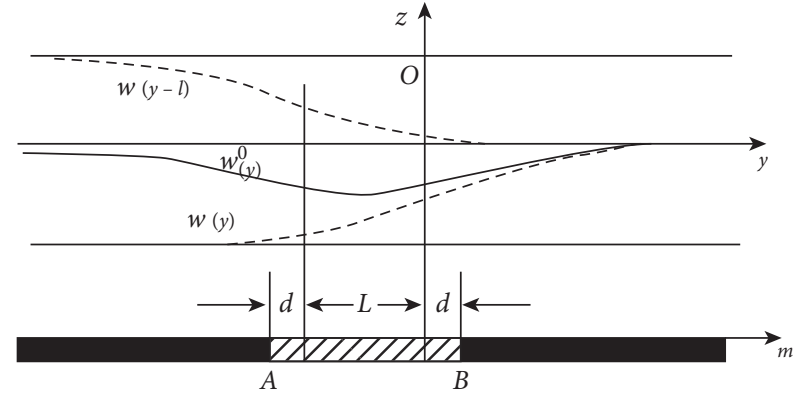

FIGURE 7: Semi-infinite stacking algorithm.

play a decisive role in the surface movement and deformation speed and duration [57-59]. When the working face advances longer and the surface subsidence is larger, the subsidence speed is faster; as the mining depth increases, the maximum surface subsidence speed gradually decreases. Combined with relevant research literature, the maximum surface subsidence speed is proportional to the maximum surface subsidence value, working face advancing speed, and subsidence coefficient and inversely proportional to the mining depth, and the maximum subsidence speed of repeated mining is greater than that of the initial mining, and its relationship expression is shown in

$$
V_{\max }=\frac{K W_{\max } V}{H_{0}}
$$

where $V_{\max }$ is the maximum sinking speed of the ground $(\mathrm{mm} / \mathrm{d}) ; K$ is the subsidence coefficient; $V$ is the advancing speed of working face $(\mathrm{m} / \mathrm{d}) ; H_{0}$ is the mining depth $(\mathrm{m})$; and $W_{\max }$ is the maximum sinking value, $(\mathrm{mm})$.

Generally, the surface movement and deformation will last for a long time, with an average period of $2 a-3 a$. If the roof is hard rock, this time period will last for more time, up to $6 \mathrm{~A}$. According to the surface monitoring data, when the working face is mined for one year, the surface movement and deformation are gradually stable. Take the surface observation points $Z 1, Z 2$, and $Z 3$ of Hanjiawan coal mine as the research objects, respectively, and record the maximum subsidence amount, maximum subsidence speed, and duration of the three points in different periods, as shown in Table 5.

According to the monitoring results of three observation points, the initial period of surface movement and deformation in Hanjiawan coal mine is $19 \mathrm{~d}-25 \mathrm{~d}$, the active period is $90 \mathrm{~d}-99 \mathrm{~d}$, and the declining period is $200 \mathrm{~d}-205 \mathrm{~d}$. The surface movement and deformation in the mining area are in the declining period for a long time, and the surface 
TABLE 5: Surface movement and deformation parameters.

\begin{tabular}{|c|c|c|c|c|c|c|c|c|}
\hline \multirow[b]{2}{*}{ Number } & \multirow{2}{*}{$\begin{array}{c}\text { Maximum subsidence } \\
(\mathrm{mm})\end{array}$} & \multirow{2}{*}{$\begin{array}{l}\text { Maximum sinking speed } \\
(\mathrm{mm} / \mathrm{d})\end{array}$} & \multicolumn{2}{|c|}{ Initial period } & \multicolumn{2}{|c|}{ Active period } & \multicolumn{2}{|c|}{ Decline period } \\
\hline & & & $\begin{array}{l}\text { Time } \\
\text { (d) }\end{array}$ & Sink $(\mathrm{mm})$ & Time (d) & Sink $(\mathrm{mm})$ & Time (d) & Sink $(\mathrm{mm})$ \\
\hline$\overline{\mathrm{Z} 1}$ & 1878 & 83 & 23 & 17 & 92 & 1815 & 203 & 46 \\
\hline $\mathrm{Z} 2$ & 1931 & 85 & 24 & 16 & 96 & 1876 & 203 & 39 \\
\hline $\mathrm{Z} 3$ & 1963 & 86 & 25 & 15 & 99 & 1913 & 205 & 35 \\
\hline
\end{tabular}

change tends to be stable during this period. The initial subsidence of the surface is $81 \mathrm{~mm}-86 \mathrm{~mm}$, and the subsidence of the active period is $180 \mathrm{~mm}$. The subsidence is $2 \mathrm{~mm}-1913 \mathrm{~mm}$, the subsidence is $31 \mathrm{~mm}-46 \mathrm{~mm}$ in the recession period, and the surface subsidence speed is the fastest in the active period, and the maximum subsidence reaches $1963 \mathrm{~mm}$. Under the special geological mining conditions of Hanjiawan coal mine, the maximum subsidence speed of the surface movement and deformation in the active period can reach $86 \mathrm{~mm} / \mathrm{d}$.

\section{Numerical Simulation}

\subsection{Model Building Process}

5.1.1. Model Building. To further study the influence of geomorphic types on the surface movement and deformation due to mineral exploitation in the loess gully area, we take the 12106 mining face of the Hanjiawan coal mine as the research object. Because the loess gully area is in a special natural environment, characterized by a large loess coverage thickness and a high degree of vertical fracture development, the mining area has a unique geomorphology [60]. The surface elevation ranges from $+1150 \mathrm{~m}$ to $+1320 \mathrm{~m}$, with an average elevation of $+1235 \mathrm{~m}$. The research area of the Hanjiawan coal mine is $3 \mathrm{D}$ modeled using FLAC3D based on the Mohr-Coulomb criterion. As shown in Figure 8, the strike length ( $x$ direction) of the model is $600 \mathrm{~m}$, the dip length ( $Y$ direction) is $400 \mathrm{~m}$, the maximum length in the $Z$ direction is $300 \mathrm{~m}$, the width of the 12106 working face is $253 \mathrm{~m}$, and the average thickness of the mining coal seam is $6.5 \mathrm{~m}$. The constraint mode of the 3D model is based on the boundary displacement constraint. According to the data, the $X, Y$, and $Z$ directions are all constrained by the bottom, with the $X$ and $Y$ directions constraining the boundary displacement at both ends. The model is divided into 25061 elements and 61227 nodes.

5.1.2. Boundary Condition. In this model, normal constraints are set on the sides of the model to limit the horizontal movement of the model; vertical and horizontal constraints are set on the bottom boundary of the model to limit the horizontal and vertical displacement of the model; the top surface of the model is a free boundary.

5.1.3. Profile Position. According to the mining influence range of the 12106 working face, the research content is based on the slope mass of different angles to simulate the stability of the slope mass after mining. The $X$-direction

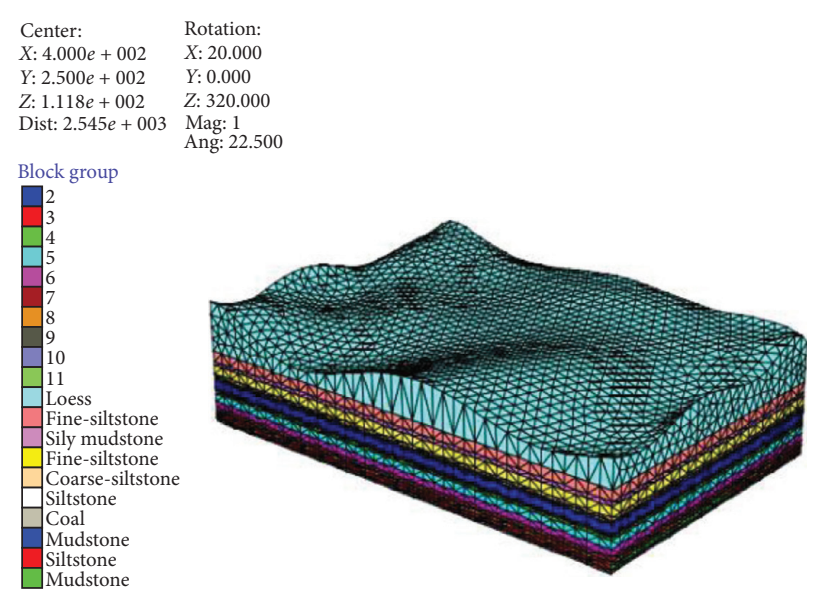

FIgURE 8: Three-dimensional model of the study area.

length of the established model is $500 \mathrm{~m}$, the coal seam excavation range is $50-280 \mathrm{~m}$, and the excavation length is $130 \mathrm{~m}$, which is consistent with the actual mining length of the working face. The thickness of the mining coal seam is $2 \mathrm{~m}$, and the inclination angle of the coal seam and bedrock is $24^{\circ}$. We set the four sides and bottom of the model as fixed surfaces, and the top as the free surface. We then simulate the in situ stress to simplify the treatment, with the self-weight stress as the initial equilibrium stress. The numerical simulation of the working face mining is performed after the stress on the rock layer reaches the initial state. To thoroughly study the stability of the slope mass in the mining area, by comparing the mining conditions of different slopes, we study the effects of high and low slopes of the working face on the surface displacement vector and the mechanism of disaster formation, respectively. Figure 9 shows the profile positions of the different slopes.

The excavation area of the 12106 working face is $130 \mathrm{~m} \times 230 \mathrm{~m}$. Taking the mining face line as the starting point and with an excavation step distance of $50 \mathrm{~m}$, we proceed from the west to the east along the direction of the cut and ultimately to the end of the mining face stop line. We then make a profile based on the working surface tendency, adjust the slope angle, and analyze the horizontal and vertical displacement vectors and the destruction characteristics of the plastic zone.

5.1.4. Calculation Parameters. The numerical simulation results show that the determination of the geotechnical mechanical parameters plays a decisive role in the reliability 


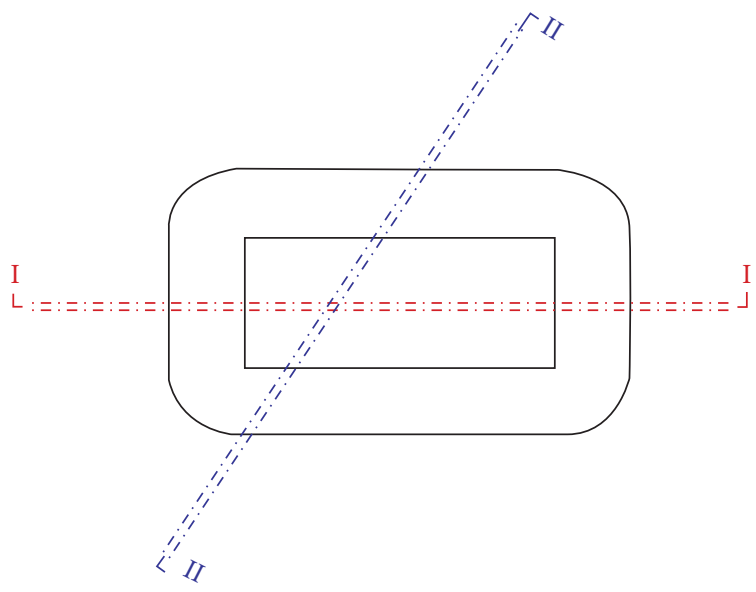

FIgURE 9: Different slope profile positions.

TABle 6: Physical mechanics parameters.

\begin{tabular}{lcccccc}
\hline Lithology & Density $\left(\mathrm{kg} / \mathrm{m}^{3}\right)$ & Elastic modulus $(\mathrm{MPa})$ & Poisson's ratio & Tensile strength $(\mathrm{MPa})$ & Cohesion $(\mathrm{MPa})$ & Internal angle $\left(^{\circ}\right)$ \\
\hline Loess & 2125 & 20 & 0.4 & 0.0031 & 0.021 & 16 \\
Fine-siltstone & 2410 & 10210 & 0.3 & 0.62 & 1.12 & 35 \\
Argillaceous rock & 2630 & 850 & 0.3 & 0.23 & 2.35 & 2.53 \\
Coal & 670 & 2300 & 0.3 & 1.23 & 2.27 & 37 \\
Mudstone & 1481 & 2421 & 0.4 & 0.7 & 1.35 \\
Siltstone & 1633 & & & & & 25 \\
\hline
\end{tabular}

of the numerical simulation results $[61,62]$. To make the numerical simulation more in line with the actual conditions, we obtained the mechanical characteristics and physical parameters of the coal seam and overlying rock layer based on the engineering geological conditions of the mining area and the rock mechanics experimental results, as listed in Table 6.

\subsection{Calculation Results}

5.2.1. Horizontal Displacement. Figure 10 shows the horizontal displacement vector of the 12106 working face with different slopes. The horizontal displacement clouds obtained at different angles show that (1) when the slope is $60^{\circ}$, the top displacement of the slope is the largest, and the maximum displacement is $70 \mathrm{~cm}$. The peak displacement of the slope appears at the top of the slope; because the slope is affected by tension and compression, the displacement from the top to the foot is uneven, the displacement at the top of the slope changes significantly, the integrity of the slope mass is destroyed, and the overall tendency is to move to the foot of the slope. (2) When the slope is $30^{\circ}$, the slope displacement decreases in the horizontal direction, and the overall movement of the slope displacement is uniform, no large landslides occur, and the slope is relatively stable without any rain erosion.

When the surface is disturbed by external forces, there will be signs of a collapse. The mining activity causes the overlying rock layer to move and deform. The loosely accumulated soil layer is cut along the slope to become a block. The slope mass loses continuity, and a nonuniform gravity action comes into play. The slope foot loses support and forms an uneven slump. The cut slope mass is affected by gravity, which reduces the friction coefficient between the loose soil body and the bedrock surface, resulting in a landslide.

5.2.2. Vertical Displacement. Figure 11 shows the vertical displacement vector of the 12106 working face with different slopes. As shown in the vertical displacement vector diagram, at the lowest point of the slope, the caving zone develops directly to the surface. With the continuous development of the mining face in the mining area, the overburden layer collapses due to roof pressure. When the slope angle is $60^{\circ}$, the fracture zone of the rock layer spreads to the slope surface, thus damaging the side slope and increasing the risk of a landslide and collapse. When the slope angle is $30^{\circ}$, the slope bears the overburden, the self-weight is low, and the caving zone is not developed; in this case, the surface of the slope mass remains unaffected, thus ensuring the integrity of the slope. When the working face is mined to the valley, because the seam at the bottom of the valley is buried shallowly, the development of the caving zone spreads to the surface. In addition to the formation of a rock fracture zone, the rock fracture is directly connected to the working face. Washed by the rain, the loess at the bottom of the valley flows directly into the working face through the fracture zone, forming a landslide or collapse pit. At the same time, with the advance of the working face, the fracture and caving zones of the rock stratum develop 


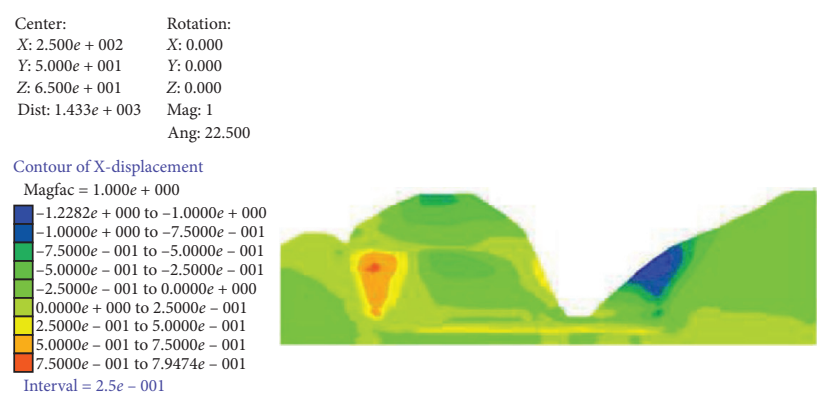

(a)

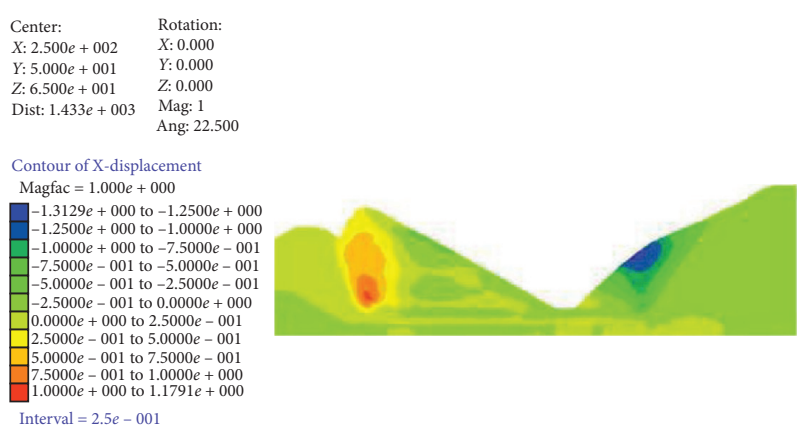

(b)

Figure 10: Horizontal displacement vectors of the 12106 working face with slope angles of (a) $60^{\circ}$; (b) $30^{\circ}$.

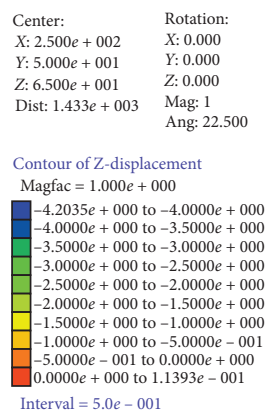

Interval $=5.0 e-001$

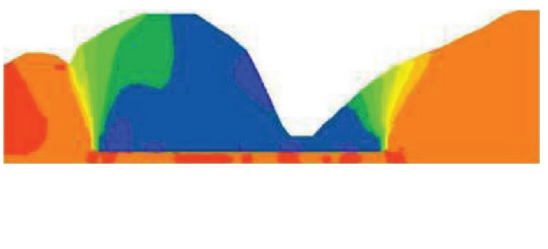

(a)

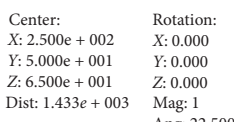

Dist: $1.4330+003$ Z: 0.000

Ang: 22.500

Contour of Z-displacement

Magfac $=1.000 e+000$

$-4.1328 e+000$ to $-4.0000 e+000$

.

$-3.0000 e+000$ to $-2.5000 e+000$

$5000 e+000$ to $-2.0000 e+000$

$0000 e+000$ to $-1.5000 e+000$

-

.

$.0000 e-001$ to $0.0000 e+000$
$.0000 e+000$ to $3.6467 e-003$

Interval $=5.0 e-001$

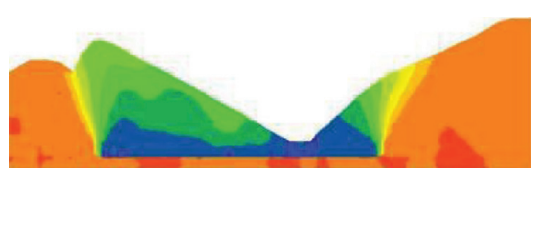

(b)

Figure 11: Vertical displacement vectors of the 12106 working face with slope angles of (a) $60^{\circ}$; (b) $30^{\circ}$.

directly to the surface. The surface moves, deforms, and sinks, and the slope mass slips, causing the surface to sink and collapse.

5.2.3. Plastic Zone. Figure 12 shows the failure distribution map of the 12106 working face in the plastic zone of different slopes. Based on the distribution map of the plastic failure in the mining process at different slope angles of the working face, it can be seen that, in the mining process of the working face from the top to the bottom, the rock fracture around the working face moves to the lower part of the slope mass, and then the plastic failure area in the surrounding rock continues to gradually expand to the surface and slope mass. At the end of the mining face, the collapse of the overlying strata affects the surface, the integrity of the slope structure is destroyed, and the overall tendency is to develop towards the bottom of the slope. This can cause local landslides, collapses, and other disasters.

Based on the above analysis, mining causes the overlying rock to move and deform, and the loosely accumulated soil layer is cut on the slope to become a block, the slope loses continuity, and the effect of gravity becomes uneven. After the coal seam at the slope foot is mined, the slope is cut, and the aggravated gravity of the slope reduces the friction coefficient between the loose soil and the bedrock surface, resulting in landslides. Field observation and numerical simulation both show that the slope angle has the greatest influence on slope stability. The numerical simulation result is lower than the field observation data, though the difference between the two is insignificant. The error is mainly due to the simplification of the rock parameters in the modeling process. $\mathrm{Nu}$ merical simulation has partially simplified the geological conditions and removed some of the thinner and weak rock layers, which increased the proportion of hard rock layers in the overlying rock layers, which is conducive to controlling surface subsidence and slope movement.

\section{Discussion}

Based on the geological conditions of the loess gully area and combined with surface monitoring data of the mining area and numerical simulation results, we studied the slope stability under different slope angles. From the comprehensive analysis of actual mining surface disasters in Hanjiawan coal mine, we can discuss the results in the following three aspects.

(1) When the slope inclination angle is less than $30^{\circ}$, the horizontal displacement of the entire slope rock and soil mass is evidently reduced, it is relatively uniform, and only a large slope slip occurs. When there is no erosion due to rain, the horizontal displacement is relatively stable.

(2) When the slope angle is between $30^{\circ}$ and $60^{\circ}$, the maximum horizontal displacement of the ditch slope appears in the middle of the slope. Mining causes cracks in the middle of the slope to expand and 


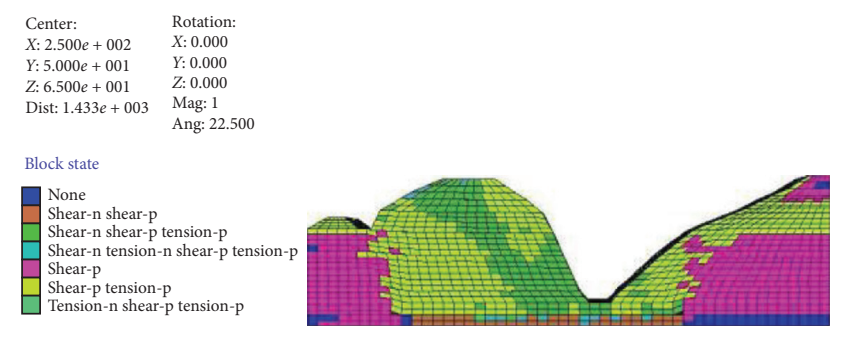

(a)

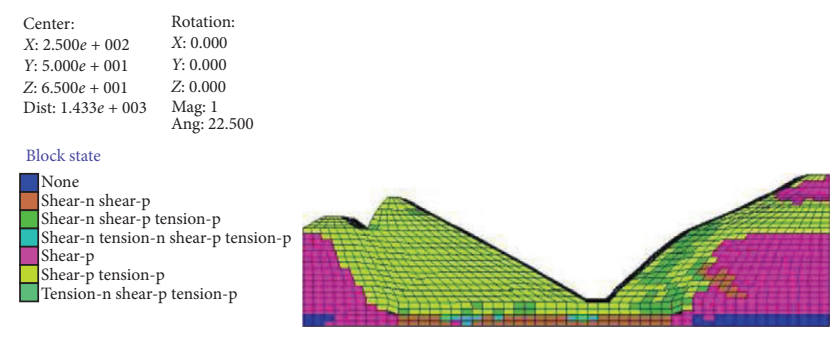

(b)

FIgURe 12: Distribution law of the plastic zone under different slopes: (a) $60^{\circ}$; (b) $30^{\circ}$.

develop, forming step cracks perpendicular to the slope of the ditch, and the ditch is cut. Driven by the cracked block of the slope, a dynamic landslide occurs.

(3) When the slope angle is greater than $60^{\circ}$, the largest horizontal displacement of the slope appears at the top of the slope. The top displacement of the slope is significant, reaching more than $70 \mathrm{~cm}$, and the horizontal displacement of the slope is uneven. Generally, the top displacement is large, and the slope displacement in the direction of the foot gradually decreases, which causes the rock at the top of the slope to lose support and collapse, leading to collapse disasters.

The impact of mining on the slope is bounded by the crack angle. The crack angle cuts and separates the rock and soil layers of the slope. As the working face continues to advance, the crack failure area of the slope expands. Under the weight of the slope, the crack becomes wider. A collapse disaster occurs in a steeper part. When the working face advances to the position of the slope toe, the slope toe loses support, the movement of the slope body accelerates, and the slope body becomes unstable, which causes the entire slope body to collapse.

\section{Conclusions}

Based on the formation mechanism and disaster occurrence conditions of landslides due to mining in a loess gully area and combined with the characteristics of the overburden rock structure in this area, we studied the rock and soil mechanical parameters of the slope mass and employed the FLAC3D software to simulate the occurrence mechanism of landslides at different slopes in the mining area. The following conclusions can be drawn from the study results:

The mining face was affected by mining, and the overlying rock layer was distorted due to compression. Under the influence of mining, the surface cracks extended in the direction of the working face, developed to a certain depth, and were closed by tensile and compression deformation cracks. The development depth of the fractures could be predicted based on the development characteristics of the rock fracture zones. Due to the development of valley fissures, the loess layer shifted downward along the direction of the fracture to form a collapse, and the ground surface generated stepped ground fissures due to the discontinuous movement and deformation.

The movement and deformation of the ground surface can be characterized by three periods from the start of mining to the end of the working face: a start-up period, an active period, and a recession period. Monitoring data showed that the maximum surface subsidence reaches $1963 \mathrm{~mm}$, the maximum subsidence speed was $86 \mathrm{~mm} / \mathrm{d}$, and the surface movement deformation duration lasted up to $101 \mathrm{~d}$; with the surface movement deformation entering the recession period, the rate of change in the subsidence amount and subsidence speed no longer increases, and the surface movement tends to stabilize and approach zero.

The numerical simulation results showed that when the slope angle is greater than $60^{\circ}$, the displacement at the top of the slope is large, and the displacements at the top, middle, and bottom of the slope were uneven. At this time, the cracks on the rock layer developed to the surface, and a sliding surface of the bedrock surface was formed. Under the condition of rain erosion and the weight of the bedrock, the friction coefficient of the sliding surface decreased, resulting in a landslide.

\section{Data Availability}

The data used to support the findings of this study are available from the corresponding author upon request.

\section{Conflicts of Interest}

The authors declare no conflicts of interest.

\section{Acknowledgments}

The authors thank the National Natural Science Foundation of China for its support to this study. This research was funded by the National Natural Science Foundation of China (Grant nos. 51874230 and 52074208).

\section{References}

[1] L. Patané, "Bio-inspired robotic solutions for landslide monitoring," Energies, vol. 12, no. 7, p. 1256, 2019.

[2] Z. Cao, Y. Li, Y. Liu, Y. Chen, and Y. Wang, "When and where did the Loess Plateau turn "green"? analysis of the tendency and breakpoints of the normalized difference vegetation index," Land Degradation \& Development, vol. 29, no. 1, pp. 162-175, 2018. 
[3] O. Hungr, S. Leroueil, and L. Picarelli, "The Varnes classification of landslide types, an update," Landslides, vol. 11, no. 2, pp. 167-194, 2014.

[4] C. Yuan and H. Moayedi, "Evaluation and comparison of the advanced metaheuristic and conventional machine learning methods for the prediction of landslide occurrence," Engineering with Computers, vol. 36, no. 4, pp. 1801-1811, 2019.

[5] H. Q. Zhao, W. B. Zhang, Z. Z. Zhu, and X. Zhao, "Analysis on susceptibility of vegetation canopy spectra in coal mining area to land reclamation," Spectroscopy and Spectral Analysis, vol. 39, no. 6, pp. 1858-1863, 2019.

[6] X. Y. Yu, C. Mu, and D. D. Zhang, "Assessment of land reclamation benefits in mining areas using fuzzy comprehensive evaluation," Sustainability, vol. 12, no. 5, p. 2015, 2020.

[7] W. Chen, X. Xie, J. Wang et al., "A comparative study of logistic model tree, random forest, and classification and regression tree models for spatial prediction of landslide susceptibility," Catena, vol. 151, no. 10, pp. 147-160, 2017.

[8] O. Ghorbanzadeh, S. Moslem, T. Blaschke, and S. Duleba, "Sustainable urban transport planning considering different stakeholder groups by an interval-AHP decision support model," Sustainability, vol. 11, no. 1, p. 9, 2019.

[9] Y. Liu, C. Xu, B. Huang et al., "Landslide displacement prediction based on multi-source data fusion and sensitivity states," Engineering Geology, vol. 12, no. 6, pp. 112-128, 2020.

[10] J. X. Xu, G. Li, G. L. Chen, and H. Zhao, "Evaluation and dynamic change of land ecological quality in mining area," Journal of China Coal Society, vol. 38, no. 8, pp. 180-185, 2013.

[11] C. Li, J. B. Zhu, and B. Wang, "Research on evolution laws and early warning criterion of deformation rate in different deformation stages of landslide," Chinese Journal of Mechanical Engineering, vol. 35, no. 11, pp. 1407-1414, 2016.

[12] L. Zhang, J. Wang, Z. Bai, and C. Lv, "Effects of vegetation on runoff and soil erosion on reclaimed land in an opencast coalmine dump in a loess area," Catena, vol. 128, pp. 44-53, 2015.

[13] X. Liu, Z. Bai, W. Zhou, Y. Cao, and G. Zhang, "Changes in soil properties in the soil profile after mining and reclamation in an opencast coal mine on the Loess Plateau, China," Ecological Engineering, vol. 98, pp. 228-239, 2017.

[14] X. F. Jin, S. C. Dong, W. Liu, and X. Li, "Study on relationship between industrial chain extension and evolution of resourcebased city-a case study on Tongling city," Economic Geography, vol. 30, no. 6, pp. 403-408, 2010.

[15] M. Zhang, Analysis of Terrain Conditions of Coal Mining Landslide in Mountain Area, Jiangsu Normal University, Xuzhou, China, 2013.

[16] C. F. Huang, Research on the Law of Surface Movement in Fully Mechanized Top Coal Caving Mining Under Thick Collapsible Loess Layer, Henan Polytechnic University, Jiaozuo, China, 2011.

[17] B. Liu, Research on Ground Movement and Deformation Laws of Mining Shallow-Buried and Near-Distance Coal Seams in the Loess Gully Region, Xi'an University of Science and Technology, Xi'an, China, 2017.

[18] O. Hungr, S. Leroueil, and L. Picarelli, "The Varnes classification of landslide types, an update," Landslides, vol. 11, no. 2, pp. 167-194, 2014.

[19] P. Audet, B. D. Pinno, and E. Thiffault, "Reclamation of boreal forest after oil sands mining: anticipating novel challenges in novel environments," Canadian Journal of Forest Research, vol. 45, no. 5, pp. 364-371, 2014.
[20] C. Zhou, Z. Gong, J. Hu, A. Cao, and H. Liang, "A cost-benefit analysis of landfill mining and material recycling in China," Waste Management, vol. 35, no. 3, pp. 191-198, 2015.

[21] D. T. Bui, T. A. Tuan, H. Klempe, B. Pradhan, and I. Revhaug, "Spatial prediction models for shallow landslide hazards: a comparative assessment of the efficacy of support vector machines, artificial neural networks, kernel logistic regression, and logistic model tree," Landslides, vol. 13, no. 2, pp. 361-378, 2016.

[22] F. Yu, J. M. Wang, and Z. K. Bai, "Effects of surface coal mining and land reclamation on soil properties: a review," Earth-Science Reviews, vol. 191, no. 5, pp. 12-25, 2019.

[23] J. Corominas, C. Van Westen, P. Frattini et al., "Recommendations for the quantitative analysis of landslide risk," Bulletin of Engineering Geology and the Environment, vol. 73, no. 2, pp. 209-263, 2014.

[24] W. Xiao, Z. Hu, Y. P. Chugh, and Y. Zhao, "Dynamic subsidence simulation and topsoil removal strategy in high groundwater table and underground coal mining area: a case study in Shandong Province," International Journal of Mining, Reclamation and Environment, vol. 28, no. 4, pp. 250-263, 2014.

[25] Y.-C. Weng, T. Fujiwara, H. J. Houng, C.-H. Sun, W.-Y. Li, and Y.-W. Kuo, "Management of landfill reclamation with regard to biodiversity preservation, global warming mitigation and landfill mining: experiences from the Asia-Pacific region," Journal of Cleaner Production, vol. 104, no. 4, pp. 364-373, 2015.

[26] A. Lucieer, S. M. D. Jong, and D. Turner, "Mapping landslide displacements using structure from motion (SfM) and image correlation of multi-temporal UAV photography," Progress in Physical Geography: Earth and Environment, vol. 38, no. 1, pp. 97-116, 2014.

[27] Y. Z. Chang and S. C. Dong, "Evaluation of sustainable development of resources-based cities in Shanxi Province based on unascertained measure," Sustainability, vol. 8, no. 1, p. 585, 2016.

[28] C. Y. Guo, Z. Q. Liu, and C. Y. Zhang, "Evaluation on the express enterprise's service quality of customers perception based on SPSS and unascertained measure model," Chinese Journal of Mechanical Engineering, vol. 9, no. 5, pp. 17-26, 2016.

[29] M. S. Tehrany, B. Pradhan, and M. N. Jebur, "Flood susceptibility mapping using a novel ensemble weights-of-evidence and support vector machine models in GIS," Journal of Hydrology, vol. 512, pp. 332-343, 2014.

[30] A. Trigila, C. Iadanza, C. Esposito, and G. Scarascia-Mugnozza, "Comparison of logistic regression and random forests techniques for shallow landslide susceptibility assessment in Giampilieri (NE Sicily, Italy)," Geomorphology, vol. 249, pp. 119-136, 2015.

[31] B. Y. Yang, Z. K. Bai, Y. G. Cao et al., "Dynamic changes in carbon seques-tration from opencast mining activities and land reclamation in China's Loess Plateau," Sustainability, vol. 11, no. 3, p. 1473, 2019.

[32] S. C. Li, J. Wu, Z. H. Xu, and L. P. Li, "Unascertained measure model of water and mud inrush risk evaluation in karst tunnels and its engineering application," KSCE Journal of Civil Engineering, vol. 21, no. 4, pp. 1170-1182, 2017.

[33] Y.-L. Hu, Z.-X. Niu, D.-H. Zeng, and C.-Y. Wang, "Soil amendment improves tree growth and soil carbon and nitrogen pools in Mongolian pine plantations on post-mining land in Northeast China," Land Degradation \& Development, vol. 26, no. 8, pp. 807-812, 2015. 
[34] F. Gutiérrez, M. Parise, J. De Waele, and H. Jourde, "A review on natural and human-induced geohazards and impacts in karst," Earth-Science Reviews, vol. 138, no. 3, pp. 61-88, 2014.

[35] W. Chen, J. Peng, H. Hong et al., "Landslide susceptibility modelling using GIS-based machine learning techniques for Chongren County, Jiangxi Province, China," Science of the Total Environment, vol. 626, no. 2, pp. 1121-1135, 2018.

[36] W. Chen, X. Yan, Z. Zhao, H. Hong, D. T. Bui, and B. Pradhan, "Spatial prediction of landslide susceptibility using data mining-based kernel logistic regression, Naive Bayes and RBF network models for the Long County area (China)," Bulletin of Engineering Geology and the Environment, vol. 78, no. 1, pp. 247-266, 2019.

[37] B. T. Pham, D. Tien Bui, I. Prakash, and M. B. Dholakia, "Rotation forest fuzzy rule-based classifier ensemble for spatial prediction of landslides using GIS," Natural Hazards, vol. 83, no. 1, pp. 97-127, 2016.

[38] C. A. Abaidoo, E. M. O. Jnr, A. Arko-Adjei, and B. E. K. Prah, "Monitoring the extent of reclamation of small scale mining areas using artificial neural networks," Heliyon, vol. 5, no. 3, pp. 1445-1449, 2019.

[39] J. Y. Ma, Z. B. Li, and B. Ma, "Influences of revegetation mode on soil water dynamic in gully slope of the Chinese Loess Hilly-Gully region," Natural Hazards, vol. 52, no. 1, pp. 1-22, 2020.

[40] E. Bakhtavar, R. Aghayarloo, S. Yousefi, K. Hewage, and R. Sadiq, "Renewable energy based mine reclamation strategy: a hybrid fuzzy-based network analysis," Journal of Cleaner Production, vol. 230, no. 2, pp. 253-263, 2019.

[41] H. Shen, F. Zheng, L. Wen, Y. Han, and W. Hu, "Impacts of rainfall intensity and slope gradient on rill erosion processes at loessial hillslope," Soil and Tillage Research, vol. 155, pp. 429-436, 2016.

[42] Z. Xin, Y. Qin, and X. Yu, "Spatial variability in soil organic carbon and its influencing factors in a hilly watershed of the Loess Plateau, China," Catena, vol. 137, no. 5, pp. 660-669, 2016.

[43] M. Koopialipoor, D. Jahed Armaghani, A. Hedayat, A. Marto, and B. Gordan, "Applying various hybrid intelligent systems to evaluate and predict slope stability under static and dynamic conditions," Soft Computing, vol. 23, no. 14, pp. 5913-5929, 2019.

[44] J. Wang, Q. Qin, and Z. Bai, "Characterizing the effects of opencast coal-mining and land reclamation on soil macropore distribution characteristics using 3D CT scanning," Catena, vol. 171, no. 1, pp. 212-221, 2018.

[45] H. Zhu, L. M. Zhang, T. Xiao, and X. Y. Li, "Enhancement of slope stability by vegetation considering uncertainties in root distribution," Computers and Geotechnics, vol. 85, no. 4, pp. 84-89, 2017.

[46] A. Canal and M. Akin, "Assessment of rock slope stability by probabilistic-based slope stability probability classification method along highway cut slopes in Adilcevaz-Bitlis (Turkey)," Journal of Mountain Science, vol. 13, no. 11, pp. 1893-1909, 2016.

[47] T. Litman, "Developing Indicators for comprehensive and sustainable transport planning," Transportation Research Record, vol. 43, no. 3, pp. 10-15, 2007.

[48] D. Stead, "The influence of shales on slope instability," Rock Mechanics and Rock Engineering, vol. 49, no. 2, pp. 635-651, 2016.

[49] D. P. Deng and L. Li, "Limit equilibrium analysis of slope stability with coupling nonlinear strength criterion and double-strength reduction technique," International Journal of Geomechanics, vol. 19, no. 6, pp. 112-128, 2019.

[50] T. W. Zhang, Q. X. Cai, L. Han, J. S. Shu, and W. Zhou, "3D stability analysis method of concave slope based on the Bishop method," International Journal of Mining Science and Technology, vol. 27, no. 6, pp. 365-370, 2017.

[51] H. Lin, W. Zhong, and P. Cao, "Three-dimensional rock slope stability analysis considering the surface load distribution," European Journal of Environmental and Civil Engineering, vol. 20, no. 8, pp. 877-898, 2016.

[52] X. G. Song, C. X. Chen, K. Z. Xia et al., "Analysis of the surface deformation characteristics and strata movement mechanism in the main shaft area of Chengchao iron mine," Environmental Earth Sciences, vol. 9, no. 7, p. 335, 2018.

[53] J. B. Peng, L. W. Chen, Q. B. Huang et al., "Large-scale physical simulative experiment on ground-fissure expansion mechanism," Chinese Journal of Geophysics, vol. 51, no. 3, pp. 1826-1834, 2008.

[54] G. Cheng, C. Chen, T. Ma, H. Liu, and C. Tang, "A case study on the strata movement mechanism and surface deformation regulation in Chengchao underground iron mine," Rock Mechanics and Rock Engineering, vol. 50, no. 4, pp.1011-1032, 2017.

[55] W. Zhang, D. S. Zhang, L. X. Wu, and H. Z. Wang, "On-site radon detection of mining-induced fractures from overlying strata to the surface: a case study of the Baoshan Coal Mine in China," Energies, vol. 7, no. 12, pp. 8483-8507, 2017.

[56] D. Xu, S. Peng, S. Xiang, and Y. He, "A novel caving model of overburden strata movement induced by coal mining," Energies, vol. 10, no. 4, p. 476, 2017.

[57] G. Xu, J. Zhang, H. Liu, and C. Ren, "Shanghai center project excavation induced ground surface movements and deformations," Frontiers of Structural and Civil Engineering, vol. 12, no. 1, pp. 26-43, 2018.

[58] F. D. Nicola, P. De Pace, and M. A. Hernandez, "Comovement of major energy, agricultural, and food commodity price returns: a time-series assessment," Energy Economics, vol. 57, no. 2, pp. 28-41, 2016.

[59] A. A. Malinowska, W. T. Witkowski, A. Guzy, and R. Hejmanowski, "Mapping ground movements caused by mining-induced earthquakes applying satellite radar interferometry," Engineering Geology, vol. 246, no. 3, pp. 402-411, 2018.

[60] Q. Ji, E. Bouri, D. Roubaud, and S. J. H. Shahzad, "Risk spillover between energy and agricultural commodity markets: a dependence-switching CoVaR-copula model," Energy Economics, vol. 75, no. 2, pp. 14-27, 2018.

[61] C. Zhao, D. Jin, J. Geng, and Q. Sun, "Numerical simulation of the groundwater system for mining shallow buried coal seams in the ecologically fragile areas of Western China," Mine Water and the Environment, vol. 38, no. 1, pp. 158-165, 2019.

[62] H. Y. Yin, S. Z. Sang, D. L. Xie et al., "A numerical simulation technique to study fault activation characteristics during mining between fault bundles," Environmental Earth Sciences, vol. 78, no. 5, pp. 148-162, 2019.

[63] H. Y. Fang, L. Y. Sun, and Z. H. Tang, "Effects of rainfall and slope on runoff, soil erosion and rill development: an experimental study using two loess soils," Hydrological Processes, vol. 29, no. 11, pp. 2649-2658, 2015. 